\title{
Evaluation of environmental impacts of harvest residue-based bioenergy using radiative forcing analysis
}

\author{
by Francesca Pierobon ${ }^{1}$, Indroneil Ganguly ${ }^{2, *}$, Tommaso Anfodillo and Ivan L. Eastin²
}

\begin{abstract}
The "carbon neutrality" assumption plays an important role in the evaluation of the global warming potential (GWP) of bioenergy relative to fossil fuels. In the case of woody bioenergy, this assumption implies that the carbon dioxide emitted during the combustion of the biomass is equal to the carbon dioxide sequestered from the atmosphere within that biomass. However, the collection and conversion of woody biomass requires energy inputs in various forms that produce emissions to the air or water. To be able to estimate the overall environmental burdens associated with converting woody biomass to bioenergy, and the net reduction in greenhouse gas (GHG) emissions to the atmosphere by avoiding the use of fossil fuel, a life cycle assessment (LCA) is the internationally recognized method of choice. However, the carbon neutrality of woody biomass and the environmental impacts associated with wood-based bioenergy are hotly debated in national and international arenas. This study presents a comprehensive evaluation of the environmental impacts of woody biomass-based bioenergy and proposes a GWP impact assessment methodology using radiative forcing for incorporating the dynamics of carbon sequestration, decomposition of residues and biomass processing in the life cycle assessment of bioenergy.
\end{abstract}

Keywords: life cycle assessment, carbon neutrality, radiative forcing, bioenergy

\section{RÉSUMÉ}

L'hypothèse du « bilan neutre » en carbone joue un rôle important dans lévaluation du potentiel de réchauffement planétaire (PRP) des bioénergies par rapport aux combustibles fossiles. Dans le cas des bioénergies tirées du bois, l'hypothèse présuppose que le dioxyde de carbone émis lors de la combustion de la biomasse est égal au dioxyde de carbone retiré de latmosphère par la biomasse. Cependant, la récolte et la transformation de la biomasse ligneuse nécessitent des apports énergétiques de différentes formes qui produisent des émissions dans lair ou l'eau. Afin dềtre en mesure destimer la charge environnementale globale associée à la transformation de la biomasse ligneuse en bioénergie, ainsi que la réduction nette des émissions de gaz à effet de serre (GES) dans latmosphère en évitant l'utilisation de combustibles fossiles, une analyse du cycle de vie (ACV) constitue la méthode internationalement reconnue. Toutefois, le bilan neutre en carbone dans le cas de la biomasse ligneuse ainsi que les impacts environnementaux associés à la bioénergie tirée du bois sont chaudement débattus sur la scène nationale et internationale. Cette étude présente une évaluation approfondie des impacts environnementaux de la bioénergie tirée de la biomasse ligneuse et propose une méthodologie dévaluation des impacts sur le PRP utilisant le forçage radiatif afin d'utiliser la dynamique de la séquestration du carbone, de la décomposition des résidus et de la transformation de la biomasse au cours de lanalyse du cycle de vie de la bioénergie.

Mots clés : analyse du cycle de vie, bilan neutre du carbone, forçage radiatif, bioénergie

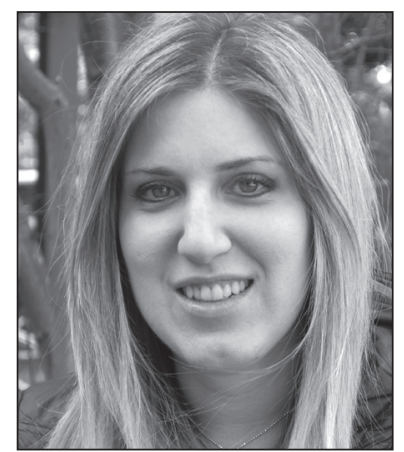

Francesca Pierobon

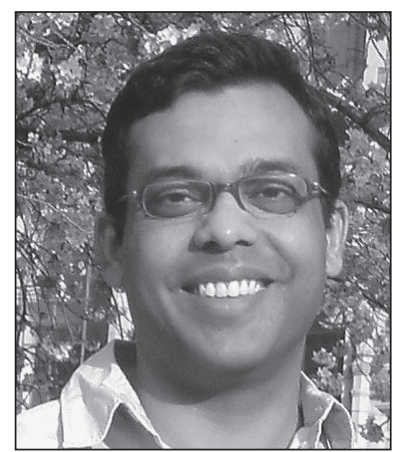

Indroneil Ganguly

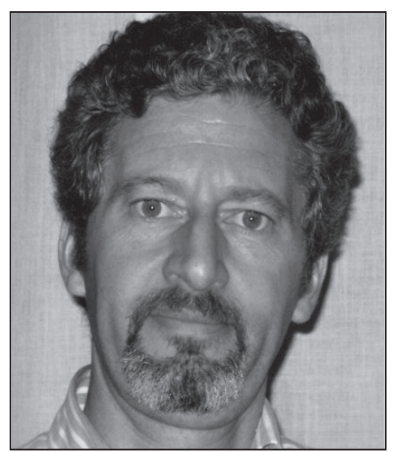

Tommaso Anfodillo

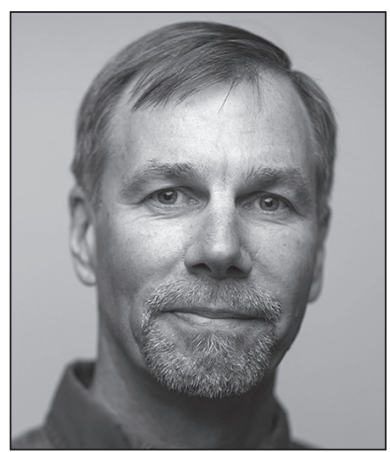

Ivan L. Eastin

\footnotetext{
${ }^{1}$ Department of Land, Environment, Agriculture and Forestry (LEAF), University of Padua, Viale dell'Università 16, 35020 Legnaro, Padua, Italy. ${ }^{2}$ Center for International Trade in Forest Products (CINTRAFOR), School of Environmental and Forest Sciences, University of Washington, Seattle, WA, USA.

*Corresponding author. E-mail: indro@uw.edu.
} 


\section{Introduction}

Life cycle assessment (LCA) is a popular tool for the compilation and evaluation of the inputs, outputs and the potential environmental impacts of a product throughout its life cycle (ISO 2006a,b). The impact categories generally included in LCA studies are global warming, ozone depletion, eutrophication, acidification, smog formation, ecotoxicity, human health criteria, human health cancer and human health non-cancer. Among these, the impact on global warming is the focal indicator for bioenergy considerations.

The impact on global warming is assessed through the evaluation of the greenhouse gas (GHG) emissions, expressed in terms of carbon dioxide equivalence $\left(\mathrm{CO}_{2 \mathrm{e}}\right)$. In the LCA framework the GHG emissions are classified in two distinct categories, fossil and biogenic. Fossil emissions are those that are released through the combustion or decomposition of fossilized material (e.g., coal, oil and natural gas). Biogenic emissions are those that are released through combustion or decomposition of biomass (i.e., material of biological origin) (BSI 2011).

Based on the International Reference Life Cycle Data System (ILCD) Handbook (Wolf et al. 2012) and the EPA accounting framework (EPA 2011), the impact on global warming is entirely attributed to fossil GHG emissions while biogenic emissions are considered to be carbon neutral and are not reported in the LCA indicators.

The carbon neutrality assumption is based on the idea that the release of carbon dioxide during the conversion of biomass to energy is balanced by the carbon sequestered within that biomass. In carbon accounting terms, carbon sequestration during biomass growth is accounted for as a negative emission. The net GHG emissions from biologically based energy products is evaluated by subtracting the amount of $\mathrm{CO}_{2}$ taken up during biomass growth in the first stage of the product life cycle from the amount of $\mathrm{CO}_{2}$ (including biogenic) released to the atmosphere during all life cycle stages of the product (Brandão et al. 2013). Among the new and developing approaches, the ISO 14067 (ISO 2013) and GHG Protocol (GHG Protocol 2011), as well as the revised Publicly Available Specification (BSI 2011), require that the biogenic contribution be excluded from the accounting although it may be calculated and reported separately.

The assumption of carbon neutrality is adopted in conventional LCA since the timing of emissions relative to removals is not considered. For this reason, the benefit to temporarily removing carbon from the atmosphere is not assigned. As observed by Brandão et al. (2013), although the net exchange may be the same, their different timing with respect to the order of uptake and release of carbon will lead to different trajectories of atmospheric $\mathrm{CO}_{2}$ concentrations.

Various methods have been proposed for considering the dynamics of the carbon cycle in assessing sequestration and temporary storage of carbon and delayed GHG emissions. The two most popular methods in the literature are the Moura-Costa method and the Lashof accounting method (Sathre and Gustavsson 2012). These methods evaluate the impact on global warming using the radiative forcing approach and produce equivalence factors that can be used to account for carbon storage based on the number of years the carbon is sequestered. However, these methods do not include the temporal dynamics of emissions and sequestration.

The LCA approach that considers the temporal distribution of GHG emissions over the life cycle of a product is known as "dynamic LCA". Dynamic LCA utilizes the radiative forcing metrics to produce dynamic characterization factors. These dynamic characterization factors are then used to substitute for the characterization factors used in the traditional LCA (Brandão et al. 2013). The dynamic LCA has recently been adopted to evaluate the impact of renewable resources (Kirkinen et al. 2008, Kendall et al. 2009, O'Hare et al. 2009, Levasseur et al. 2010). Cherubini et al. (2011a,b) applied the radiative forcing approach to calculate the integrated impact of carbon uptake during biomass growth in the forest with GHG emissions during biomass burns using an analytical model. However, no auxiliary life cycle inputs for harvesting and biomass processing were considered in this study.

\section{Study Objective}

The objective of this study was to develop a dynamic LCA of residual woody biomass-based bioenergy by incorporating the temporal aspect of carbon sequestration. The woody feedstock in this study was residual woody biomass that was left in slash piles at the harvest landing following a commercial harvest (clearcut/commercial thinning) operation. Hence, this study incorporated the dynamic nature of carbon sequestration in the overall supply chain LCA of woody biomass-based bioenergy. The specific objectives of this study were to:

1. perform a "cradle-to-grave" life-cycle assessment of woody biomass-based bioenergy,

2. evaluate the temporal dynamics of carbon sequestration and decomposition of residues in a particular forest type in the Pacific Northwest region, and

3. apply a radiative forcing analysis that incorporates the temporal aspect of carbon sequestration within an LCA framework.

\section{Materials and Methods}

\section{Area of study}

The geographic area of the study can significantly influence the LCA results because of differences in forest management intensity or the type of forest. This paper focuses on the industrial forest land and forestry practices in the Pacific Northwest (PNW) region west of the Cascade mountains. Specifically, for this study the forest inventory data (FIA 2014) for industrial forest land in Grays Harbor County, Washington State were used. This county was selected for its abundance of commercial forest lands, which are typical of the commercial forest lands located in western Washington and Oregon. Moreover, easy access to state and national highways makes this region ideal for the production of woody biomass.

\section{System boundary}

The system boundary for the study, shown in Fig. 1, comprises all of the biomass harvest, collection, and in-woods processing-related activities. The system boundary for this study also included transportation of the woody biomass from the forest to a hypothetical bioenergy facility as well as the end of life use (e.g., domestic heating).

The functional unit for the study was 1 bone-dry metric ton (BDmT) of woody biomass and the LCA approach is a cradleto-grave analysis. The time frame of the evaluation was 100 years (as recommended by the ISO guidelines). 


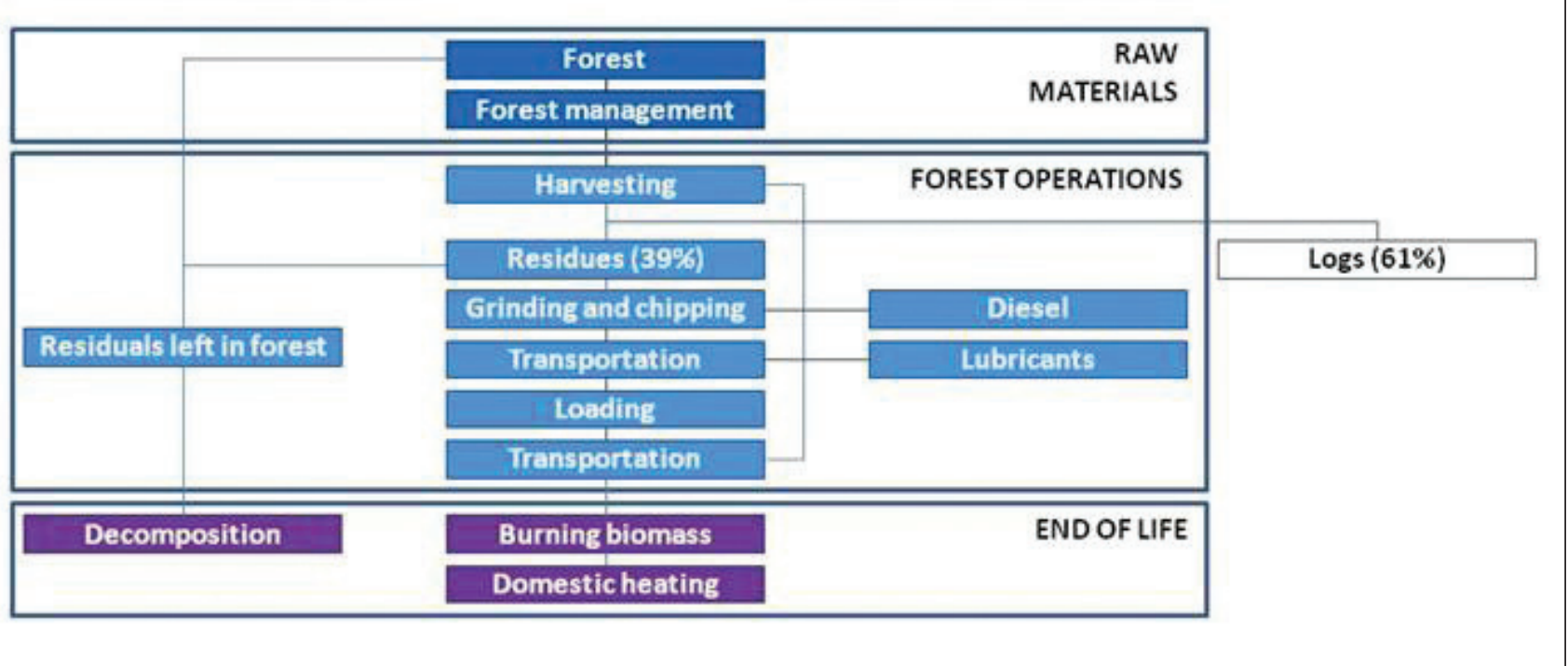

Fig. 1. System boundaries for the LCA.

\section{Carbon sequestration}

A representation of the carbon cycle in forests is shown in Fig. 2. Carbon dioxide is absorbed from the atmosphere by trees through photosynthesis and transformed into biomass during growth. A fraction of the carbon absorbed is then returned to the atmosphere through respiration or from natural disturbances (e.g., fire), which not only emit $\mathrm{CO}_{2}$ but also other pollutants, including $\mathrm{N}_{2} \mathrm{O}, \mathrm{CH}_{4}, \mathrm{NO}_{\mathrm{x}}, \mathrm{NMVOC}$ and $\mathrm{CO}$. In addition, some biomass remains in the forest where it is transferred into dead organic matter pools (i.e., dead wood and litter), some of which decomposes quickly, returning carbon to the atmosphere, while the remainder can be stored for longer periods of time.

In this study the carbon sequestration from the aboveground biomass (i.e., tree tops and branches) has been taken into account and modeled. The below-ground biomass (i.e., tree stumps and roots) was explicitly excluded from the study.

The predominant forest type in the study region is industrial Douglas-fir plantation forest with an average rotation period of between 40 and 50 years. Accordingly, for this study the representative plot was assumed to be a Douglas-fir plantation forest

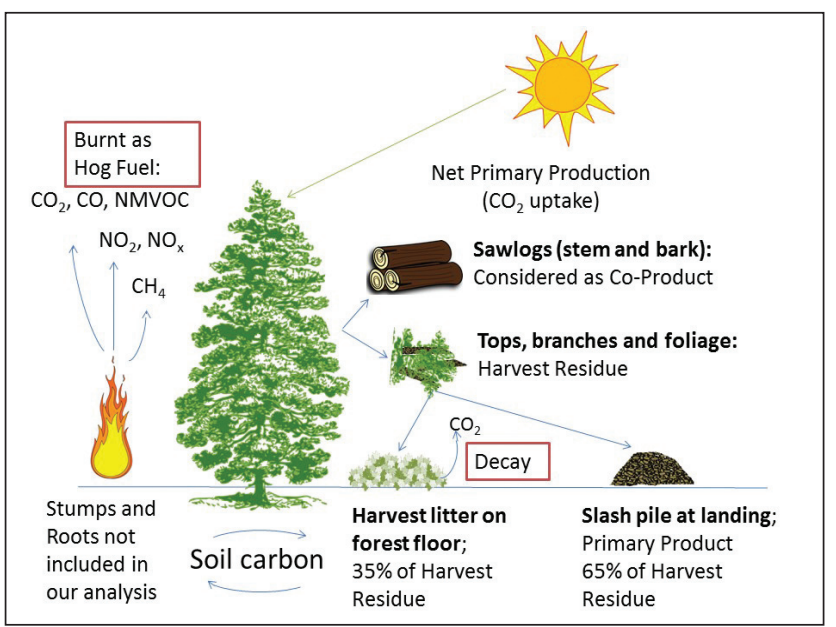

Fig. 2. Representation of the carbon balance in the forest. with a rotation age of 45 years. The temporal carbon sequestration during forest growth was calculated using the Forest Vegetation Simulator (FVS). FVS is an empirical forest growth simulation model that represents different geographic areas across the United States. The model simulates forest growth in response to natural succession, disturbances and management actions. A simulation was run to generate results at five-year intervals using the Pacific Northwest Coast (PN) Variant.

The results of the model provide carbon stocks for standing and harvested biomass for the various tree components: stems, tops, foliage, branches, bark, roots and stumps. For this paper, the volume of standing carbon was calculated. The stem and bark volumes were attributed to logs while tops and branches were defined as residues. The harvest residual biomass-based bioenergy from the tops and branches was selected for the analysis in this paper.

The FVS simulation was run for a 45 -year rotation period extending from 2014 to 2059. According to the IPCC Guidelines, the amount of $\mathrm{CO}_{2}$ that is absorbed from the atmosphere and converted into biogenic carbon can be estimated by multiplying the difference in the carbon stocks (carbon sinks) between two subsequent years by the molecular weight of $\mathrm{CO}_{2}$ and dividing this number by the molecular weight of carbon (IPCC 2006):

$$
C_{s B q}=\Delta C \cdot \frac{M W_{C O_{2}}}{M W_{C}}
$$

where $C_{\text {seq }}=$ carbon sequestered, $\Delta C=$ difference of carbon stocks between two subsequent years, $M W_{\mathrm{CO}_{2}}=$ Molecular weight of $\mathrm{CO}_{2}(44 \mathrm{~kg} / \mathrm{kmol})$, and $M W_{C}=$ Molecular weight of carbon $(12 \mathrm{~kg} / \mathrm{kmol}$ ) (IPCC 2006).

To incorporate the sequestered carbon into the LCA, the functional unit of wood has been tracked from the biomass growth in the forest through to its end of life. For this reason it is necessary to refer the total amount of carbon sequestration to the functional unit of the system by multiplying by the ratio between the total amount of carbon dioxide corresponding to the harvested biomass and the amount of carbon dioxide corresponding to the functional unit. In this study the functional unit of analysis was $1 \mathrm{BDmT}$ of wood, which was 
produced by harvesting $1.7 \mathrm{BDmT}$ of trees, which equals $3.117 \mathrm{MgCO}_{2 \mathrm{e}}$. The remaining 0.7 BDmT of biomass was harvest residues that are left in the forest to naturally decompose or be burned in a prescribed burn.

\section{Harvest operations}

Forest operations include a combination of technologies and practices that differ from site to site based on the topography of the forest area and the type of forest management practice adopted. In this study, forest operations were categorized into five primary processes: 1) harvesting, 2) grinding and chipping, 3) secondary transportation, 4) loading, and 5) primary transportation. Data on harvest operations were used from the CORRIM Phase I and CORRIM Phase II reports (Bowyer et al. 2004, Lippke et al. 2011).

Harvest operations consist of all the activities involved in cutting down a standing tree in the forest. Harvest operations in the PNW region often utilize the whole-tree harvesting method. This is an economically preferable method of harvesting trees that allows for the removal of limbs and tops at the harvest landing and reduces the requirements for subsequent slash disposal across the harvest site. Processing harvested trees at the landing include bucking, delimbing, and/or topping to remove the non-merchantable limbs and tops from the logs. Alternatively, lower-quality trees, including tops and branches, are often simply chipped entirely.

Two primary products are obtained through these harvesting processes: logs and harvest residues. Logs are the primary product and they have the highest economic value. Normally, residues are not considered an important product since they have little economic value and are thus considered to be a waste material. However, in this study the harvest residues were the product of interest. The harvest residues (i.e., branches and tops of trees) are passed through a grinding or chipping machine that reduces them to a more compactable and transportable size. The grinder/chipper is fed from the slash piles located at the landing zone using a separate loader.

The harvest residues are transported from the harvest area to a loading zone located near the forest road. This is a secondary transportation process that often consists of skidding the trees/ residues on gentle slopes or yarding them on steep slopes. The residues are then loaded onto haul vehicles and are transported from the woods to a processing point (primary transportation).

Recovery of residue from sites in the mountainous PNW region faces physical restrictions, especially with respect to the road network required to haul the material. In most chipping and grinding operations, biomass material is transported on highways in $91.8-\mathrm{m}^{3}$ and $107.1-\mathrm{m}^{3}$ (120 or 140 cubic yard [CY]) chip vans. When these chip vans are attached to highway tractors, the combined units have a turning radius that exceeds the design radius of curves on the lowest standard of forest roads. As a result, there are many forest sites where chip vans cannot access the log landings and therefore the biomass material must be shuttled from the landing using shorter-wheelbase dump trucks.
In this study the harvest residuals were ground/chipped at the primary landing location and shuttled in a dump truck to a secondary landing. It was assumed in this study that $65 \%$ of the harvest residuals (tops and branches) were transported to the primary landing while the remaining residuals were left scattered on the forest floor.

The data used for the LCA analysis related to the hourly consumption of diesel fuel and lubricants as well as the time of operation for the machines and transport trucks are summarized in Tables 1 and 2, respectively.

Emission factors related to the fuel consumed and fertilizer used were developed from the SimaPro v.7.3 model, with an environmental impact analysis that utilized the TRACI2, v.3.3 method (Tool for the Reduction and Assessment of Chemical and other Environmental Impacts) developed by the US Environmental Protection Agency ${ }^{1}$.

As outlined previously, two products-logs and harvest residuals-were generated during the harvest process. When more than one product is produced by a single process, an allocation of the environmental impacts is required. Allocation is defined as: "Partitioning the inputs to, or emissions from, a shared process or a product system between the product system under study and one or more other product systems" (BSI 2011). An allocation of impacts between the two products is required, which means that it is necessary to attribute energy and material flows to the products in different ratios based on a set of specific criteria. In general, there are two types of allocation systems used in LCA: mass allocation and economic allocation.

A mass allocation was used in this study, since the economic value of forest residuals is not well established. Impacts are allocated between the logs and residuals in relation to the

${ }^{1}$ http://www.epa.gov/nrmrl/std/traci/traci.html 
percentage of the mass of each unit of wood extracted from the forest. Based on FVS model estimates, $80 \%$ of the above ground biomass is allocated to sawlogs (stem and bark) and $20 \%$ of the above ground biomass is allocated to harvest residuals (tops, branches and foliage).

\section{Residues left in the forest}

As previously noted, the assumption used in the study is that in order to produce $1 \mathrm{BDmT}$ of biomass, $1.7 \mathrm{BDmT}$ of wood needs to be harvested. In most forest operations, $0.7 \mathrm{BDmT}$ of residual biomass is typically left behind on the forest floor as well as at the landing due to breakage/loss during the harvest, skidding and loading operations. Harvest residues left on the forest floor have an impact on the net emission profile since they decompose over time, releasing GHGs back into the atmosphere.

The dynamic decay of harvest residuals left on the forest floor depends on the physical characteristics of the timber species as well as the environmental conditions. These factors determine the rate of decay of the woody biomass and the ratio of biomass that decomposes versus that which remains in the forest, increasing the soil carbon. The composition of the emissions released depends on the chemistry of the reaction: if the reaction occurs under aerobic conditions, the biomass will decompose by reaction with oxygen, thereby releasing $\mathrm{CO}_{2}$ into the atmosphere. If the reaction occurs under anaerobic conditions, $\mathrm{CH}_{4}$ can be produced during decomposition, which substantially increases the impact on climate change. The decomposition of biomass left in forest follows an exponential decay function (EIA 2006):

$$
f(t)=Q \cdot e^{k\left(t-t_{0}\right)}
$$

where $f(t)=$ total biomass at time $t, Q=$ total biomass at time $t$, and $k=$ decomposition rate $(k=0.021$ weighted value was used assuming 50\% Douglas-fir, $25 \%$ ponderosa pine, $25 \%$ lodgepole pine (EIA 2006: Table 3.6).

The quantity of decomposed biomass over time equals the difference between the volume of biomass at time $t$ and $t_{0}$ and is evaluated through the derivative of the biomass decay function, which is expressed by the following equation:

$$
f^{\prime}(t)=k \cdot Q \cdot e^{k\left(t-t_{0}\right)}
$$

where $f^{\prime}(t)=$ decomposed biomass.

It has been assumed that $90 \%$ of the biomass left in the forest decomposes over the reference time horizon, while $10 \%$ remains in the forest and contributes to an increase in the soil carbon. In addition, aerobic conditions have been assumed.

To evaluate the amount of $\mathrm{CO}_{2}$ released into the atmosphere as the harvest residuals decay, it is necessary to convert the amount of decomposed biomass $f^{\prime}(t)$ to the amount of carbon by multiplying by 0.5 and then converting the amount of carbon to $\mathrm{CO}_{2}$.

\section{Burning biomass}

At the end of these processes, the biomass is burned to produce energy for domestic heating and energy production. The burning of woody biomass emits a variety of gases and aerosols to the atmosphere, including carbon dioxide $\left(\mathrm{CO}_{2}\right)$, carbon monoxide $(\mathrm{CO})$, nitrogen oxides $\left(\mathrm{NO}_{\mathrm{x}}\right)$, volatile and semi-volatile organic compounds (VOC and SVOC), particulate matter (PM), ammonia $\left(\mathrm{NH}_{3}\right)$, sulfur dioxide $\left(\mathrm{SO}_{2}\right)$ and methane $\left(\mathrm{CH}_{4}\right)$ (Wiedinmyer and Neff 2007), which significantly contributes to global warming.
Table 3. Emissions to air from the burning of $1 \mathrm{BDmT}$ of biomass.

\begin{tabular}{lcc}
\hline Substance & Unit & Total \\
\hline Carbon dioxide & $\mathrm{Mg}$ & 1.57 \\
Methane & $\mathrm{Mg}$ & $2.03 \mathrm{E}-03$ \\
Carbon monoxide & $\mathrm{Mg}$ & $3.02 \mathrm{E}-02$ \\
NMVOC & $\mathrm{Mg}$ & $1.94 \mathrm{E}-03$ \\
Dust (unspecified) & $\mathrm{Mg}$ & $6.58 \mathrm{E}-03$ \\
Dust (PM 10) & $\mathrm{Mg}$ & $4.13 \mathrm{E}-03$ \\
Dust (PM 2.5) & $\mathrm{Mg}$ & $3.67 \mathrm{E}-03$ \\
Elemental carbon & $\mathrm{Mg}$ & $2.64 \mathrm{E}-04$ \\
Organic carbon & $\mathrm{Mg}$ & $1.98 \mathrm{E}-03$ \\
Nitrogen oxides & $\mathrm{Mg}$ & $2.50 \mathrm{E}-03$ \\
Ammonia & $\mathrm{Mg}$ & $2.21 \mathrm{E}-04$ \\
VOC & $\mathrm{Mg}$ & $2.57 \mathrm{E}-03$ \\
Sulphur dioxide & $\mathrm{Mg}$ & $8.30 \mathrm{E}-04$ \\
Methanol & $\mathrm{Mg}$ & $2.99 \mathrm{E}-04$ \\
Formaldehyde & $\mathrm{Mg}$ & $4.83 \mathrm{E}-04$ \\
\hline
\end{tabular}

Gases emitted during the combustion of woody biomass can affect air quality because they are responsible for the formation of global tropospheric ozone $\left(\mathrm{O}_{3}\right) . \mathrm{O}_{3}$ is formed by the oxidizing power of the hydroxyl radical $(\mathrm{OH})$ that is produced by the photolysis of some oxygenated Non-Methane Organic Compound (NMOC) and $\mathrm{O}_{3}$, which reacts with carbon monoxide and NMOC (Akagi et al. 2011).

The IPCC global climate change report has linked most of these emissions with a variety of environmental problems, including climate change (IPCC 2007). Thus, this study is focused on GHG emissions, as expressed in terms of the carbon dioxide equivalent. The values of emissions from burning biomass have been extracted from the NETL Life Cycle Inventory Data (NETL 2013) and are reported in Table 3.

\section{Evaluation of the impact on global warming through radiative forcing}

The dynamics of carbon uptake and release have been accounted for in the evaluation of the impact on global warming through the radiative forcing (RF) analysis, where a positive radiative forcing causes a warming effect on the system while a negative radiative forcing produces a cooling effect (IPCC 2007).

Radiative forcing is the product of the time-dependent abundance of the GHG by its radiative efficiency. The radiative efficiency is defined as the RF per unit mass increase in the atmospheric abundance of the GHG. The time-dependent abundance of the GHG is evaluated through the GHG decay functions of a pulse of emissions.

The impact on global warming of each GHG is then expressed in terms of the impact of $\mathrm{CO}_{2}$ through the Global Warming Potential. The Global Warming Potential (GWP) index is based on the time-integrated global mean RF of a pulse of $1 \mathrm{~kg}$ of emissions of a component i relative to that of $1 \mathrm{~kg}$ of the reference gas $\mathrm{CO}_{2}$. The GWP of component $\mathrm{i}$ is defined by the equation (IPCC 2007):

$$
G W P_{i}=\frac{\int_{0}^{\mathrm{TH}} \mathrm{RF}_{\mathrm{i}}(\mathrm{t}) \mathrm{dt}}{\int_{0}^{\mathrm{TH}} \mathrm{RF}_{\mathrm{r}}(\mathrm{t}) \mathrm{dt}}=\frac{\int_{0}^{\mathrm{TH}} \mathrm{a}_{\mathrm{i}}\left[\mathrm{C}_{\mathrm{i}}(\mathrm{t})\right] \mathrm{dt}}{\int_{0}^{\mathrm{TH}} \mathrm{a}_{\mathrm{r}}\left[\mathrm{C}_{\mathrm{r}}(\mathrm{t})\right] \mathrm{dt}}
$$


where $\mathrm{TH}=$ time horizon, $\mathrm{RF}_{\mathrm{i}}=$ global mean $\mathrm{RF}$ of component $\mathrm{i}, \mathrm{a}_{\mathrm{i}}=\mathrm{RF}$ per unit mass increase in the atmospheric abundance of component $\mathrm{i}$ (Radiative Efficiency), and $\left[\mathrm{C}_{\mathrm{i}}(\mathrm{t})\right]=$ timedependent abundance of $i$ and the corresponding quantities for the reference gas $(r)$ in the denominator.

The decay function has been applied to the greenhouse gas emissions (carbon dioxide and other GHGs) for all phases of the life cycle assessment. The temporal aspect has been evaluated considering the cumulative value of emissions over the time period, which influences the radiative forcing. The decay of a pulse of GHGs ( $\mathrm{CO}_{2}$ excluded) follows a first-order decay equation in the function of its lifetime in the atmosphere (IPCC 2007):

$$
C(t)=e^{-\frac{t}{\tau}}
$$

where $\tau=$ lifetime ( $\tau=12$ years for methane; $\tau=114$ years for nitrous dioxide).

The decay of a pulse of $\mathrm{CO}_{2}$ at time $t$ is based on the revised version of the Bern Carbon cycle model and is given by (IPCC 2007):

$$
a_{0}+\sum_{i=1}^{3} a_{i} e^{-t / \tau_{i}}
$$

where $\mathrm{a}_{0}=0.217, \mathrm{a}_{1}=0.259, \mathrm{a}_{2}=0.338, \mathrm{a}_{3}=0.186$ and $\tau_{1}=172.9$ years, $\tau_{2}=18.51$ years, $\tau_{3}=1.186$ years.

Applying the above equation to a unit of $\mathrm{CO}_{2}$, the initial quantity of emissions is expected to decrease to 0.36 units after 100 years and to 0.23 units after 500 years. A residual of roughly 0.22 units is expected to remain in the atmosphere "for many millennia" (IPCC 2007), or even forever, if the underlying equation is assumed to be applicable for $t=\infty$ (Müller-Wenk and Brandão 2010). The decay rates for a unit-pulse of different GHGs are shown in Fig. 3.

If the emission of GHG is not a pulse but it is released over time, then the decay function applies to any yearly release of emissions over the entire time frame. The integral can be approximated with the sum of the products of the time-dependent abundance of the GHG by its radiative efficiency:

$$
R F_{\text {cum }}=\int_{0}^{T H} a_{i} \cdot\left[C_{i}(t)\right] d t \approx \sum_{i=0}^{T H} a_{i} \cdot\left[C_{i}(t)\right]
$$

Also, if the emission is not unitary it is necessary to multiply the time-dependent abundance of the GHG by its annual emission and use the appropriate value of radiative efficiency:

$$
\begin{aligned}
& {\left[C_{i}(t)\right]=C(t) \cdot y_{i}(t)} \\
& y_{i}(t)=a_{0}+\sum_{i=1}^{3} a_{i} e^{-\frac{t}{\tau_{i}}}
\end{aligned}
$$

In the case of carbon sequestration, $\mathrm{CO}_{2}$ is absorbed by the tree from the atmosphere. This process can be considered as a negative emission and its RF is negative. Also, the sequestered carbon has to be scaled back to the functional unit (1.7 BDmT of wood is harvested in order to produce $1 \mathrm{BDmT}$ of biomass).
The methodology then has to be applied to the results of the LCA. The reference period is 100 years (as recommended by the ISO). The radiative efficiency for $\mathrm{CO}_{2}$ has been assumed to be constant and equal to $1.8 \times 10^{-15} \mathrm{Wm}^{-2} \cdot \mathrm{kg}^{-1}$ evaluated through the GWP. The radiative efficiency is a function of the greenhouse gas concentration in the atmosphere but it has been assumed to be constant based on the assumption that the emissions produced throughout the life cycle of the product do not significantly modify the overall global concentration of the greenhouse gases in the atmosphere.

\section{Results}

Our results have been calculated using the following emission and uptake considerations: 1) carbon sequestration, 2) forest operations, 3) biomass burn and 4) decomposition of harvest residues left on the forest floor and at the roadside landing. Fig. 4 shows the carbon dioxide absorbed during the forest rotation period per functional unit based on the results of the FVS model. The results show that in the West Cascades region of the PNW, based on a rotation period of 45 years, the carbon dioxide absorption, as a result of biomass growth, reaches a maximum value between the $16^{\text {th }}$ and $20^{\text {th }}$ years.

The graphs were produced by normalizing the carbon sequestration to the functional unit, $1 \mathrm{BDmT}$ of harvest residue delivered to the bioenergy facility. The results of the evaluation of the GHG emissions from the forest operations obtained from the SimaPro software are shown in Table 4. The total equivalent carbon dioxide is equal to $55.33 \mathrm{kgCO}_{2 \mathrm{e}}$ and is distributed between different GHGs as shown in Table 4 .

The total emission from burning the biomass is equal to 1.62 $\mathrm{MgCO}_{2 \mathrm{e}}$. Both emissions from forest operations and burning biomass have been considered to occur at time zero, corresponding to the year when the biomass was harvested. Fig. 5 represents the decomposition of the harvest residues left in the forest. Per functional unit, a total of $0.7 \mathrm{BDmT}$ of residues are left in the forest to decompose. In this case carbon dioxide is slowly released over 100 years, which is included in the estimate of the global warming potential.

The results produced from the radiative forcing analysis are shown in Fig. 6. Emissions that occur at time zero (i.e., forest operations and burning biomass) exponentially decay over time following the specific GHGs decay functions.

For removals and emissions that occur along different temporal paths (i.e., carbon sequestration and decomposition

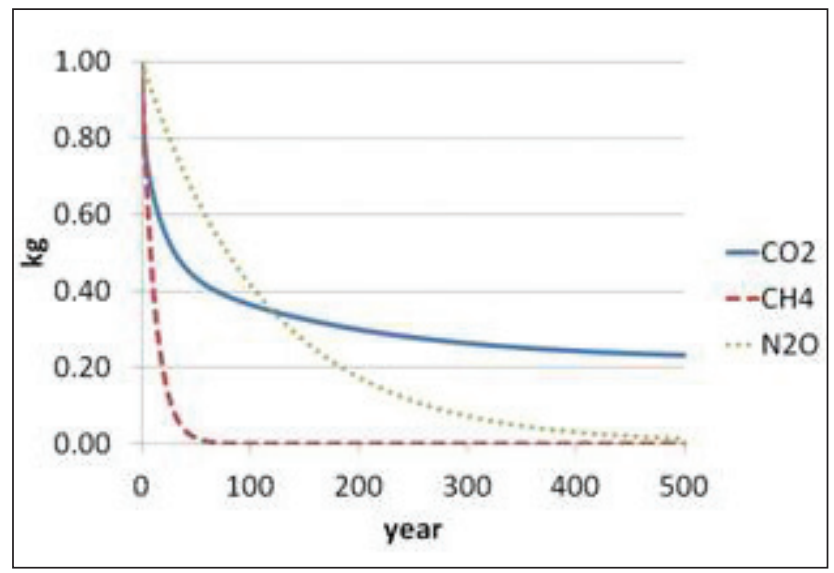

Fig. 3. Decay function of GHGs in the atmosphere. 


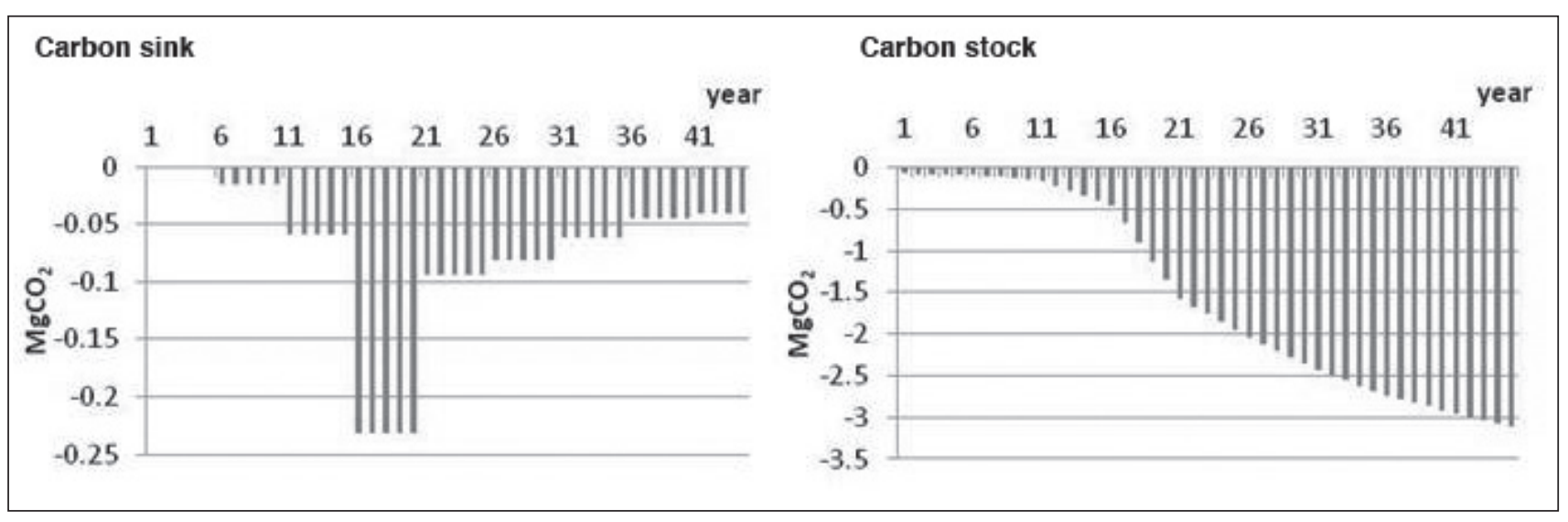

Fig. 4. Biomass growth during subsequent years (carbon sink - left panel) and accumulated biomass (carbon stock - right panel) over time normalized to the functional unit ( 1 BDmT) expressed in terms of carbon dioxide absorbed.

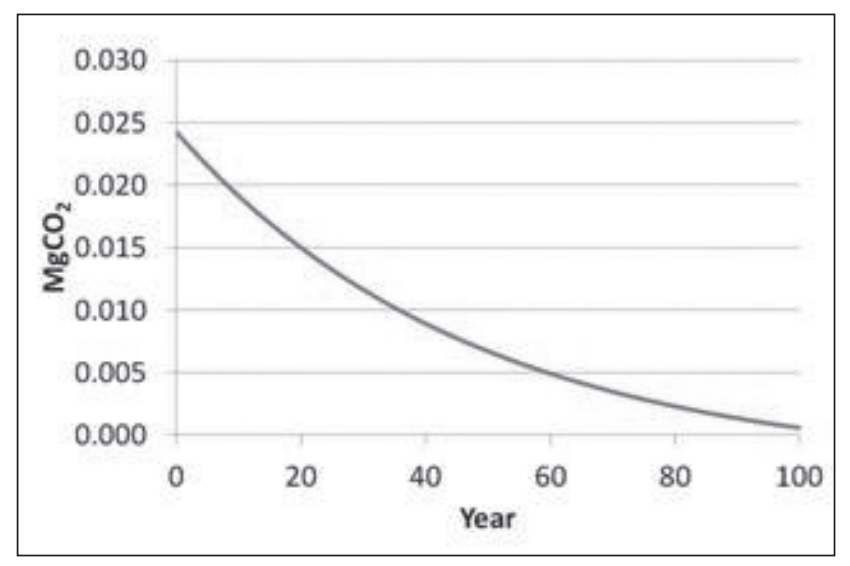

Fig. 5. Decomposition of harvest residues left on the forest floor.

of residues) the result is a cumulative effect on radiative forcing that is specific for the dynamic obtained by applying the decay function of the emission at any time and summing the contributions. For the decomposition of harvest residues, the progressive reduction of the emission release is reflected by the cumulative radiative forcing function, which progressively reduces the rate of growth.

For the carbon sequestration, the cumulative radiative forcing is the sum of the radiative forcing of a variable level of

Table 4. Greenhouse gas emission from forest operations.

\begin{tabular}{lcc}
\hline Substance & Unit & Total \\
\hline Carbon dioxide, fossil & $\mathrm{kg}$ & 53.47 \\
Methane & $\mathrm{g}$ & 69.18 \\
Methane, fossil & $\mathrm{g}$ & 4.94 \\
Dinitrogen monoxide & $\mathrm{mg}$ & 41.97 \\
Methane, dichloro-, HCC-30 & $\mathrm{mg}$ & 357.22 \\
Methane, dichlorodifluoro-, CFC-12 & $\mathrm{mg}$ & 1.92 \\
Ethane, 1,1,1-trichloro-, HCFC-140 & $\mathrm{mg}$ & 1.55 \\
Methane, tetrachloro-, CFC-10 & $\mathrm{ng}$ & 191.83 \\
Methane, monochloro-, R-40 & $\mathrm{ng}$ & 98.58 \\
Methane, bromo-, Halon 1001 & $\mathrm{ng}$ & 29.76 \\
\hline
\end{tabular}

carbon dioxide sequestration over the rotation period. Our results show that a "Radiative Forcing Turning Point" exists. This is a point at which the positive cumulative radiative forcing of the emissions is fully offset by the cumulative negative radiative forcing of carbon sequestration. This study shows that the positive cumulative radiative forcing (global warming) associated with the emissions from forest operations, transportation, residue decomposition and biomass burning is compensated for by the negative radiative forcing (global cooling) of the carbon sequestration within 18 years. In other words, it takes just 18 years for the carbon sequestration within the forest to offset the carbon emissions generated by harvesting and burning biomass for energy.

This study also shows that carbon sequestration plays a significant role in the carbon balance and demonstrates the environmental benefits of using woody biomass-based bioenergy. While the type of forest (species, biomass, rate of growth) and forest management system (rate of harvesting and silviculture) ultimately determine the level of environmental benefits, these benefits ultimately apply to all North American forest types.

\section{Discussion}

The assumption of carbon neutrality, which is widely used in LCA studies, asserts that the impact of carbon emissions from woody biomass are completely offset by the benefits of carbon sequestration. Based on this assumption, the LCA accounting methods (as approved by ISO) ignore all biogenic carbon emissions from biofuels, resulting in favourable GWP numbers for woody biomass-based biofuels as compared to their fossilbased counterparts. This study shows that using the dynamic LCA approach, under which the temporal nature of carbon sequestration and biogenic and non-biogenic emissions are all accounted for, also produces a favourable impact in terms of global warming.

This study outlined the crucial importance of introducing the temporal aspect in the LCA of bioenergy. For most of the products for which the LCA methodology is applied, the temporal aspect can be neglected without significantly changing the results because the life cycle of the product-from the production and acquisition of the raw materials, throughout the production, distribution and end of life-is completed in a relatively short period of time (e.g., mostly within one year). In the case of renewable energy, especially from woody biomass, 


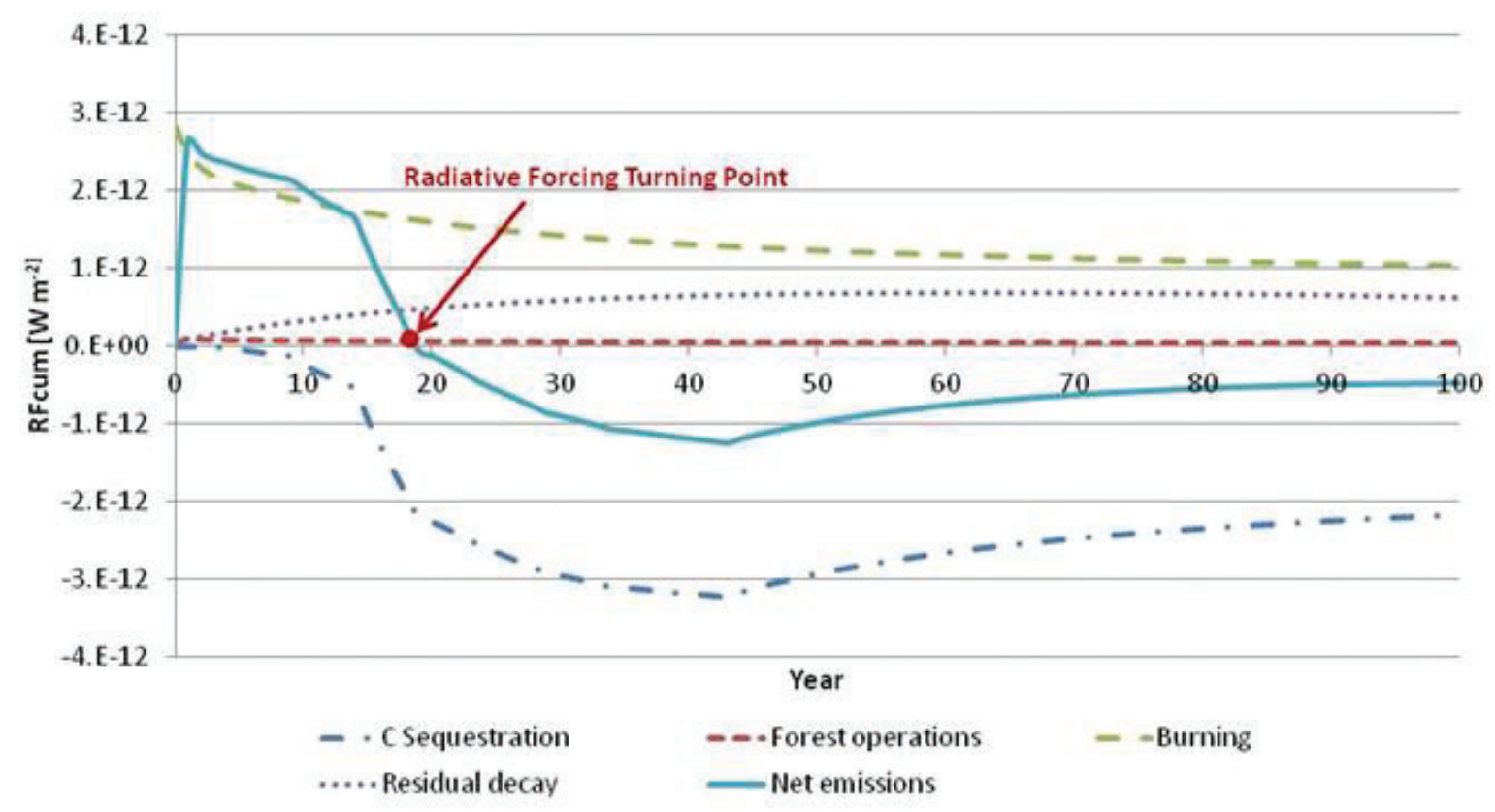

Fig. 6. Evaluation of the net impact of residual woody biomass based bioenergy on global warming using radiative forcing analysis.

the growth of the trees is based on the rotation period (ranging from 40 to 100 years), a period of time that is comparable with the time frame of evaluation of the impact on global warming. For this reason, including the dynamic of forest growth into the LCA is of crucial importance and can significantly influence the LCA results. This study highlights the fact that the global warming impact of using woody biomass for energy production is dependent on the type of forest management practice adopted and should be evaluated on a case-by-case basis.

The results of this study reinforce the importance of the time frame of the LCA-based environmental evaluation. On the one hand, the time frame of evaluation affects the values of the radiative efficiency and consequently the values of radiative forcing, and on the other hand the emissions or sequestration that occur many years after time zero will have different impacts on the evaluation based on the time frame of the study. For example, a GHG emission that occurs 90 years from time zero can have varying impacts, depending on whether the LCA time frame is 25 years, 100 years or 500 years, respectively (IPCC 2007). As outlined by Brandão et al. (2013) a very short time horizon would give too much weight to early GHG emissions (as well as to the first years of carbon storage or the first years by which emissions are delayed). Similarly, a very long time horizon would not take into account the urgency of the issue.

The limitations of this study are related to the exclusion of the below-ground biomass and soil carbon that influence the carbon balance. Furthermore, forest fires and other natural forest disturbances have not been taken into account. Forest fires have the potential of reducing the benefit of carbon sequestration on global warming because they significantly reduce the amount of above-ground biomass in the forest. Carbon sinks may also be partially compromised if the forest is subjected to natural disturbance. Thus, where data are available, a buffer should be taken into consideration to offset the possibility that a natural disturbance occurs (e.g., the risk of the spread of fires, the risk of parasite attacks, and the risk of breakage).

\section{Conclusions}

In this study, the emissions generated through feedstock collection, biomass burning and the decay of forest residuals left in the forest were compared with the carbon sequestration achieved through biomass growth within the forest. The results clearly show that the adverse global warming potential impact associated with biomass collection and burning from industrial forests in the PNW region is fully offset by the carbon sequestered during forest growth within a period of approximately 18 years. Hence, for a given region and forest management and harvest practices, the carbon neutrality of woody biomass can be generally assumed.

This study also highlights the complexity associated with the carbon neutrality assumption of the woody biomass, especially in bioenergy end-uses. Here it should be noted that this study represents a plot-level analysis and not a regional analysis. To be able to develop a comprehensive impact assessment of woody biomass-based bioenergy, a regional assessment of the specific type of bioenergy needs to be conducted after factoring in the scale of production and the corresponding biomass supply zone.

\section{Acknowledgements}

This work, as part of the Northwest Advanced Renewables Alliance (NARA), was funded by the Agriculture and Food Research Initiative Competitive Grant no. 2011-68005-30416 from the USDA National Institute of Food and Agriculture. The authors would also like to acknowledge the inputs and support provided by Mr. Tait Bowers and Mr. Jeffrey M. Comnick of the UW's School of Environmental and Forest Sciences (SEFS) for their support in various phases of this study. 


\section{References}

Akagi, S.K., R.J. Yokelson, C. Wiedinmyer, M.J. Alvarado, J.S. Reid, T. Karl, J.D. Crounse and P.O. Wennberg. 2011. Emission factors for open and domestic biomass burning for use in atmospheric models. Atmospheric Chemistry and Physics 11: 4039-4072. doi:10.5194/acp11-4039-2011, 2011.

Bowyer, J., B. Lippke, D. Briggs, J. Perez-Garcia and J. Wilson. 2004. Life cycle environmental performance of renewable materials in the context of residential building construction. Research Report No. Phase I. 43 p. Consortium for Research on Renewable Industrial Materials, Seattle, WA. Available at http://www.corrim.org/pubs/reports/2013/phase1_updates/index.asp.

Brandão, M., A. Levasseur, M.U.F. Kirschbaum, B.P. Weidema, A.L. Cowie, S.V. Jørgensen, M.Z. Hauschild, D.W. Pennington and K. Chomkhamsri. 2013. Key issues and options in accounting for carbon sequestration and temporary storage in life cycle assessment and carbon foot printing. The International Journal of Life Cycle Assessment 18: 230-240. doi:10.1007/s11367-012-0451-6.

[BSI] British Standards Institution. 2011. PAS 2050:2011 - Specification for the assessment of the life cycle greenhouse gas emission of goods and services. Available at http://shop.bsigroup.com/en/forms/ PASs/PAS-2050/.

Cherubini, F., G.P. Peters, T. Berntsen, A.H. Strømman and E. Hertwich. 2011a. $\mathrm{CO}_{2}$ emissions from biomass combustion for bioenergy: atmospheric decay and contribution to global warming. GCB Bioenergy 3: 413-426. doi:10.1111/j.1757-1707.2011.01102.x.

Cherubini, F., A.H. Strømman and E. Hertwich. 2011b. Effects of boreal forest management practices on the climate impact of $\mathrm{CO}_{2}$ emissions from bioenergy. Ecological Modelling 223: 59-66. doi:10.1016/j. ecolmodel.2011.06.021.

[EIA] U.S. Energy Information Administration. 2006. Technical Guidelines for Voluntary Reporting of Greenhouse Gas Program. Available at http://www.eia.gov/oiaf/1605.

[EPA] U.S. Environmental Protection Agency. 2011. Accounting framework for biogenic $\mathrm{CO}_{2}$ emissions from stationary sources. Office of Atmospheric Programs Climate Change Division. Washington, DC. Available at http://www.epa.gov/climatechange/Downloads/ghgemissions/Biogenic-CO2-Accounting-Framework-Report-Sept-2011.pdf.

[FIA] USDA Forest Service Forest Inventory and Analysis. 2014. Forest Inventory Data Online (FIDO) [online]. National Office, U.S. Forest Service, 1601 North Kent Street, Suite 400, Arlington, VA. Available at http://www.fia.fs.fed.us/tools-data/default.asp.

[GHG Protocol] Greenhouse Gas Protocol. 2011. Product Life Cycle Accounting and Reporting Standard. World Resources Institute and World Business Council for Sustainable Development. Available at http://www.ghgprotocol.org/standards/product-standard.

[IPCC] Intergovernmental Panel on Climate Change. 2006. Guidelines for National Greenhouse Gas Inventory. Available at http://www. ipcc-nggip.iges.or.jp/public/2006gl/.

.2007. ClimateChange2007:Thephysicalsciencebasis. Availableat http://www.ipcc.ch/publications_and_data/publications_ipcc_fourth_ assessment_report_wg1_report_the_physical_science_basis.htm.
[ISO] International Organization for Standardization. 2006a. ISO 14040. Environmental management. Life cycle assessment - Principle and Framework. Geneva. . 2006b. ISO 14044. Environmental management. Life cycle assessment - Requirements and Guidelines. Geneva.

2013. ISO/TS 14067. Greenhouse gases. Carbon footprint of products - Requirements and guidelines for quantification and communication. Geneva.

Kendall, A., B. Chang and B. Sharpe. 2009. Accounting for timedependent effects in biofuel life cycle greenhouse gas emissions calculation. Environ. Sci Technol. 43: 7142-7147.

Kirkinen, J., T. Palosuo, K. Holmgren and I. Savolainen. 2008. Greenhouse impact due to the use of combustible fuels: life cycle viewpoint and relative radiative forcing commitment. Environ Manag. 42(3): 458-469.

Levasseur, A., P. Lesage, M. Margni, L. Deschênes and R. Samson. 2010. Considering time in LCA: dynamic LCA and its application to global warming impact assessments. Environ. Sci. Technol. 44: 3169-3174.

Lippke, B., L. Johnson, J. Wilson and M. Puettmann. 2011. Life Cycle Environmental Performance of Renewable Building Materials in the Context of Residential Construction. Research Report No. Phase II. Consortium for Research on Renewable Industrial Materials, Seattle, WA. Available at http://www.corrim.org/pubs/reports/2010/phase2/ Ph2_Main_Report.pdf.

Müller-Wenk, R. and M. Brandão. 2010. Climatic impact of land use in LCA - carbon transfers between vegetation/soil and air. Int. J. Life Cycle Assess. 15: 172-182. doi:10.1007/s11367-009-0144-y.

[NETL] National Energy Technology Laboratory. 2013. NETL Life Cycle Inventory Data - Unit Process: Burning Crowns in Slash Piles. U.S. Department of Energy, National Energy Technology Laboratory. Last Updated: March 2013 (version 01). Available at www.netl.doe.gov/ LCA.

O'Hare, M., R.J. Plevin, J.I. Martin, A.D. Jones, A. Kendall and E. Hopson. 2009. Proper accounting for time increases crop-based biofuels' greenhouse gas deficit versus petroleum. Environmental Research Letters 4, 024001. doi:10.1088/1748-9326/4/2/024001.

Wiedinmyer, C. and J.C. Neff. 2007. Estimates of $\mathrm{CO}_{2}$ from fires in the United States: implications for carbon management. Carbon Balance Manage. 2: 10. doi:10.1186/1750-0680-2-10.

Sathre, R. and L. Gustavsson. 2012. Time-dependent radiative forcing effects of forest fertilization and biomass substitution. Biogeochemistry 109(1-3): 203-218.

Wolf, M.A., R. Pant, K. Chomkhamsri, S. Sala and D. Pennington. 2012. The International Reference Life Cycle Data System (ILCD) Handbook. European Commission. Joint Research Centre. Available at http://eplca.jrc.ec.europa.eu/uploads/2014/02/ JRC-Reference-Report-ILCD-Handbook-Towards-more-sustainableproduction-and-consumption-for-a-resource-efficient-Europe.pdf. 